\title{
Adolescent offenders referred to a forensic psychiatric service
}

\author{
A three-year study
}

\author{
Phil Huckle and Tegwyn Williams
}

\begin{abstract}
This paper describes the results of a survey of adolescent offenders referred to a tertiary National Health Service forensic psychiatilic service based in South Wales over a three year period. Seventy-seven adolescents aged between 13 to 18 years were seen (5.1\% of all referrals to the Service during this time). The majortly of the adolescents had committed major offences including serious sexual crime, wounding and murder. A high rate of mental disorder was observed in this survey as well as high levels of substance misuse. Elghteen per cent were admitted to a hospltal for further assessment and treatment.
\end{abstract}

Offences committed by adolescents and young adults remain a serious and increasing problem. In the period between 1989 to 1990 in the United Kingdom, the highest offending rates were found among boys aged from 15 to 18 years (Home Office, 1991). Young people between the ages of 10 to 21 years are responsible for $45 \%$ of all crimes (Times, 1994). At the time of this study, children under the age of 16 years were committing significantly more violent crimes than seven years previously (Sunday Times, 1995).

It is as important to screen for mental disorder among adolescent offenders as it is for their older counterparts. The needs of this special group of offenders are described in the Reed Report (Department of Health \& Home Office, 1992) and include careful risk assessment and care within the lowest levels of security possible. Mentally disordered adolescent offenders need a range of services, from community-based ones right up to maximum secure care. Secure placements for such adolescents are provided by a range of agencies including Social Services, the National Health Service (NHS), Youth Treatment Centres, the Special Hospitals Service Authority and the private sector (Bailey, 1993).

This paper describes a retrospective case note study of a group of adolescent offenders referred for assessment to a tertiary NHS Forensic Psychiatric Service based in South Wales, in its first three years of development.

\section{The South Wales Forensic Psychiatric Service}

The South Wales Forensic Psychiatric Service is based in the Caswell Clinic in Bridgend. It provides medium secure in-patient facilities for mentally disordered adults but also has outpatient assessment and treatment services for adolescent offenders. Referrals are accepted from a variety of agencies, including general and child and adolescent psychiatric services, agencies involved in the criminal justice system, prisons and Social Service agencies.

\section{The study}

\section{Age groups}

Seventy-seven adolescents $\mathbf{5 . 1 \%}$ of total referrals to the Service) were assessed during the period from 24th February 1992 to 24th February 1995. For data analysis, referrals were divided into two groups: the younger adolescents ( $n=15$, aged 13 to 15 years) and the older group ( $n=62$, aged 16 to 18 years).

\section{Data collection}

Information collected included clinical, sociodemographic and forensic details. All notes contained information from an informant or included extensive social histories obtained from various agencies.

The assessors were consultants or senior registrars in forensic psychiatry and forensic clinical psychologists.

\section{Gender ratio}

Of the younger adolescent group, 14 were boys. Of the older adolescent group 54 were male. 


\section{Referring agencies}

Younger adolescents (13-15-year-old group) These were referred for assessment by their solicitors (46\%); consultants in child and adolescent psychiatry (13\%); Youth Justice agencies (13\%); and other Social Service departments (13\%).

Older adolescents (16-18-year-old group)

These were referred by their solicitors $(42 \%)$; prison medical services (19\%); Social Services (16\%); Youth Justice agencies (8\%) and consultants in child and adolescent psychiatry (3\%). Fifty-six per cent of the older adolescent referrals were assessed while remanded in custody.

\section{Findings}

The offences leading to referral for assessment were usually very serious. The majority of the adolescents had extensive criminal histories.

Index offences committed by the younger adolescents

For the 13-15-year-old group the offences included sexual offences $(27 \%)$; wounding $(13 \%)$; car theft (13\%); and murder $(6.6 \%)$.

Index offences committed by the older adolescents For the 16-18-year-old group the offences included sexual offences $(9.6 \%)$; wounding $(9.6 \%)$; burglary (34\%); arson (11\%) and murder (8\%).

\section{Clinical diagnoses}

Table 1 lists the clinical diagnoses made by the assessors as recorded in the adolescents' case files. A range of mental disorders are illustrated.

Table 1. Clinical diagnoses made at the assessment interview with the adolescent

\begin{tabular}{lll}
\hline & $\begin{array}{l}13-15- \\
\text { year-olds } \\
n=15(\%)\end{array}$ & $\begin{array}{l}16-18- \\
\text { year-olds } \\
n=62(\%)\end{array}$ \\
\hline Diagnosis & $1(6.6)$ & $5(8)$ \\
\hline Schizophrenia & $1(6.6)$ & $3(4.8)$ \\
Drug-induced psychosis & 0 & $1(1.6)$ \\
Major depression & $2(13.3)$ & $4(6.5)$ \\
Mild/moderate learning disability & $1(6.6)$ & 0 \\
Obsessive-compulsive disorder & $3(20)$ & $5(8)$ \\
Conduct disorder & 0 & $5(8)$ \\
Acute reaction to stress & $4(27)$ & $25(40)$ \\
'Temperamental difficulties' & 0 & 1 \\
Minimal brain damage & 0 & 2 \\
Drug abuse & 0 & 3 \\
Personally disorder & 0 & 1 \\
Post-traumatic stress disorder & 3 & 7 \\
None & & \\
\hline
\end{tabular}

'Temperamental difficulties' was used commonly to describe behaviour which, in adults, may have resulted in the diagnosis of some form of personality disorder.

\section{Other characteristics of the adolescents assessed}

Fifty-eight per cent of the adolescents assessed had been in the care of the Local Authority at some time in their lives preceding the index offence. Fifty-two per cent had a history of alcohol abuse, and $68 \%$ of other substance misuse. Fiftyeight per cent had a history of previous psychiatric treatment preceding the index offence. Eight per cent had a history of asthma and $9 \%$ of previous head injury.

\section{History of abuse}

Table 2 shows the frequency of various forms of abuse which was confirmed by the referring agencies.

\section{Family history}

Family history of criminal behaviour was observed in $6.6 \%$ of the younger and $27 \%$ of the older adolescents referred. The family member concerned was usually the father or an older sibling.

A positive family history of psychiatric illness was seen in $20 \%$ of the younger and $21 \%$ of the older adolescents. The family member concerned was usually the mother.

A history of substance misuse in the family was found in $20 \%$ of the younger and $19 \%$ of the older adolescents. In the majority of cases the substance was alcohol.

\section{Parental separation}

Fifty-eight per cent of the adolescents assessed came from a family where the parents were separated or divorced. The average age of the adolescents at time of parental separation was 5.8 years. A further $10 \%$ had had no contact with their biological father since their birth and in a further $4 \%$ one of the parents was deceased.

Table 2. Frequency of documented abuse committed among the adolescents assessed

\begin{tabular}{lcl}
\hline Type of abuse & $\begin{array}{l}\text { 13-15-year-olds } \\
n=15(\%)\end{array}$ & $\begin{array}{l}\text { 16-year-olds } \\
n=62(\%)\end{array}$ \\
\hline Physical abuse & $8(53)$ & $21(34)$ \\
Emotional abuse & $10(67)$ & $17(27)$ \\
Sexual abuse & $3(20)$ & $12(19)$ \\
\hline
\end{tabular}


Table 3. Primary interventions offered to the mentally disordered adolescents assessed

\begin{tabular}{llc}
\hline & $\begin{array}{l}13-15- \\
\text { year-olds } \\
n=15\end{array}$ & $\begin{array}{l}16-18- \\
\text { year-olds } \\
n-62\end{array}$ \\
Interventions & 4 & 7 \\
\hline Hospltal admission & 6 & 9 \\
Supervision/probation order & 3 & 14 \\
Advice to others & 0 & 6 \\
Counselling & 0 & 7 \\
Psychotherapy & 0 & 3 \\
Change in environment & 1 & 16 \\
Court report & 0 & 1 \\
Drug education & 0 & 1 \\
1Q testing & & \\
\hline
\end{tabular}

\section{Interventions}

Table 3 lists the primary interventions made after the assessment interview. The four hospital admissions of the younger adolescents were to the only medium secure NHS unit for adolescents in the UK, the Gardener Unit based in Manchester.

The seven hospital admissions in the older age group were as follows: the Caswell Clinic $(n=2)$; general adult admission wards $(n=3)$; and a psychiatric intensive care ward $(n=2)$.

A range of community-based interventions were also recommended.

\section{Comment}

This brief survey shows a high rate of mental disorder in a group of adolescents who have committed a variety of serious offences. Seven per cent of those referred were thought to have schizophrenia at the assessment interview which had been undiagnosed previously. Bailey (1986) drew attention to the fact that some psychotic adolescents are only recognised as being mentally ill after they have committed serious crimes.

Adolescents referred for assessment at the Caswell Clinic have a similar profile to adolescents referred to the Gardener Unit for admission (Bailey et ah, 1994). These adolescents have a history of previous psychiatric contact, have been in care and show significant problems of substance abuse. Substance misuse clinics specifically for adolescents may help address this difficult and rising problem in the UK (Blennerhassett et al, 1994). Kramp et al (1987) looked at adolescent referrals to a forensic psychiatric service in Denmark and their study found similar results to ours. Adolescent offenders referred often have a family history of alcoholism and have been the victim of a variety of forms of abuse. These factors have been implicated in the development of antisocial (Pollock et al, 1990) and criminal behaviour (Widom, 1989).
Shepherd \& Farrington (1995) have suggested that the best way of preventing crime and violence is by family support, training parents, preschool education and modifying the opportunities for committing crime. Another preventive measure with regard to recidivism among adolescents is to screen for and treat any underlying mental disorder.

Forensic psychiatrists may have a role in aiding their colleagues in child and adolescent psychiatry as well as other agencies in terms of risk assessment of adolescents charged or convicted of serious crime. There are a few forensic adolescent psychiatrists in the UK. It would be useful for the forensic and child and adolescent psychiatry sections of the College to meet to discuss their respective roles in the assessment and management of the mentally disordered adolescent offender.

\section{References}

BAILY, S. M. (1986) The First Two Years of a Regional Secure Unit and Service for Adolescents - Types of Referra Made. Abstract of the Spring Meeting of the Royal College of Psychiatrists, Manchester.

- (1993) Health in young person establishments: treating the damaged and preventing harm. Criminal Behaviour and Mental Health, 3, 349-367.

- Thornton, L. \& Weaver, A. B. (1994) The first 100 admissions to an adolescent secure unit. Journal of Adolescence, 17, 207-220.

BlenNeRHASSETT, R., GILVARRY, E. \& TAYLER, P. (1994) A substance misuse clinic for adolescents. Psychiatric Bulletin, 18, 401-402.

DEPaRTMENT OF HEALTH AND HOME OFFICE (1992) Review of Health and Soctal Services for Mentally Disordered Offenders and Others Requiring Similar Services. Report of the Official Working Group Service for People with Special Needs (Reed Report). London: DoH.

HOME OFFCE (1991) Criminal Statistics for England \& Wales 1990. London: Home Office \& HMSO.

Kramp. P., IsRaelson, L., MARTENSEN, K. V., et al (1987) Serious juvenile offenders: demographic variables, diagnostic problems and therapeutic possibilities. International Journal of Law \& Psychiatry, 10, 63-73.

POLOCK, V. E., BRIERE, J., SCHNEIDER, L., et al (1990) Childhood antecedents of antisocial behaviour parental alcoholism and physical assaultiveness. American Journal of Psychiatry, 147, 1290-1293.

ShIEPHERD, J. P. \& FARRINGTON, D. (1995) Preventing crime and violence. British Medical Journal, 310, 271-272.

SUNDAY TMMS (1995) The 'savage generation' hits Britain. 5th February.

TMmas (1994) Howard toughens treatment as young offender problem grows. 22nd September.

WIDOM, C. S. (1989) The cycles of violence. Science, 244, 160-166.

*Phil Huckle, Senior Registrar in Forensic Psychiatry; and Tegwyn Williams, Consultant Forensic Psychiatrist, The South Wales Forensic Psychiatric Service, The Caswell Clinic, Glanrhyd Hospital, Bridgend CF31 4LN

*Correspondence 